\title{
Dissipation of Turbulence in the Wake of a Wind Turbine
}

\author{
J. K. Lundquist · L. Bariteau
}

Received: 16 March 2014 / Accepted: 9 October 2014 / Published online: 6 November 2014

(C) The Author(s) 2014. This article is published with open access at Springerlink.com

\begin{abstract}
The wake of a wind turbine is characterized by increased turbulence and decreased wind speed. Turbines are generally deployed in large groups in wind farms, and so the behaviour of an individual wake as it merges with other wakes and propagates downwind is critical in assessing wind-farm power production. This evolution depends on the rate of turbulence dissipation in the wind-turbine wake, which has not been previously quantified in field-scale measurements. In situ measurements of winds and turbulence dissipation from the wake region of a multi-MW turbine were collected using a tethered lifting system (TLS) carrying a payload of high-rate turbulence probes. Ambient flow measurements were provided from sonic anemometers on a meteorological tower located near the turbine. Good agreement between the tower measurements and the TLS measurements was established for a case without a wind-turbine wake. When an operating wind turbine is located between the tower and the TLS so that the wake propagates to the TLS, the TLS measures dissipation rates one to two orders of magnitude higher in the wake than outside of the wake. These data, collected between two and three rotor diameters $D$ downwind of the turbine, document the significant enhancement of turbulent kinetic energy dissipation rate within the wind-turbine wake. These wake measurements suggest that it may be useful to pursue modelling approaches that account
\end{abstract}

J. K. Lundquist $(\bowtie)$

Department of Atmospheric and Oceanic Sciences, University of Colorado

at Boulder, Boulder, CO 80309-0311, USA

e-mail: julie.lundquist@colorado.edu

J. K. Lundquist

National Wind Technology Center, National Renewable Energy Laboratory,

Golden, CO 80401-3305, USA

L. Bariteau

Earth System Research Laboratory, NOAA, 325 Broadway, Boulder, CO 80305-3337, USA

L. Bariteau

Cooperative Institute for Research in Environmental Sciences,

University of Colorado at Boulder, Boulder, CO 80309-0216, USA 
for enhanced dissipation. Comparisons of wake and non-wake dissipation rates to mean wind speed, wind-speed variance, and turbulence intensity are presented to facilitate the inclusion of these measurements in wake modelling schemes.

Keywords Dissipation rate - Tethered lifting system - Turbulent kinetic energy · Wind energy $\cdot$ Wind turbines

\section{Introduction}

Due to its appeal as a renewable, low carbon energy source, wind-energy deployment is increasing rapidly within the USA (Wiser and Bollinger 2013) and globally (GWEC 2013). Wind turbines generate electricity by extracting momentum from the atmosphere and converting it into electricity through the motion of a generator, thereby generating a wind-speed deficit downwind. Vortices are also generated as the flow moves past the blades and towers, enhancing turbulence downstream. The wind-speed deficit in a turbine's wake reduces power generated by downstream turbines (Magnusson and Smedman 1994; Barthelmie et al. 2010; Rhodes and Lundquist 2013) and may reduce power generated by distant wind farms (Kaffine and Worley 2010; Fitch et al. 2012, 2013). Similarly, the enhanced turbulence of the wake increases damaging loads on downstream turbines (Thomsen and Sørensen 1999; Kelley 2004; Kelley et al. 2004; Sim et al. 2009) and may enhance turbulent exchange with the surface (Rajewski et al. 2013). This enhanced turbulence is an important consideration for predicting the evolution of wakes from individual turbines and for understanding the processes by which individual wakes merge into larger wind-farm wakes and eventually erode downwind. Finally, global estimates of available wind resources (Jacobson and Archer 2012) rely on approximations of how turbulence dissipates downwind of an individual turbine or a group of turbines.

Although several efforts have focused on the development of numerical models for simulating wake generation, propagation, and decay (Calaf et al. 2010, 2011; Lu and Porté-Agel 2011; Churchfield et al. 2012; Mirocha et al. 2014; Aitken et al. 2014b), simulation capabilities await improvement. Measurements of dissipation rate and the resulting erosion of a turbine wake or of a wind-farm wake are required to assess models of wake behaviour that are used for optimizing wind-farm layouts or quantifying annual energy production yields at wind farms under development. Smalikho et al. (2013) showed a strong dependence of wake length with ambient background dissipation rate. Further, with the prospect of improved wake characterization on the horizon, theoretical efforts are now addressing the feasibility of optimizing wind-farm power production based on manipulating wakes (Marden et al. 2012; Farm et al. 2013). Wake characterization, particular the evolution and decay of wake vortices, is often expressed in terms of the turbulent kinetic energy (TKE) dissipation rate (Frech 2007). Numerical simulations of flow over large wind farms have suggested that the rate of TKE exchange with less turbulent and faster-moving air aloft determines how the wake region decays (Calaf et al. 2010). Wind-tunnel investigations (Hamilton et al. 2012) suggest a coupling between the dissipation rate, small-scale turbulence, and the large-scale structures of the flow in the upper portions of the wake.

Given these needs for in situ measurements of turbulence dissipation in the wake of utility-scale wind turbines in a complex atmosphere, we conducted demonstration flights of a turbulence package in the wake of a multi-MW turbine, using an established tethered lifting system (TLS) and compared measurements to those of a nearby meteorological tower with turbulence measurements. The measurement platforms and calculation methods are described 
in Sect. 2, and in Sect. 3 we describe two flights, one in undisturbed flow and one within the wake. We quantify the significant enhancement of dissipation rate observed within the wake, relate the dissipation rate to wind speed and turbulence to facilitate improvement of wake models. In Sect. 4, we summarize the results and suggest enhancements of the measurement campaign for future studies.

\section{Data and Methods}

\subsection{The University of Colorado at Boulder TLS}

The University of Colorado at Boulder's TLS is a robust, specialty-designed state-of-the art tethersonde that offers unique high resolution and highly sensitive in situ measurements of wind speed and direction, temperature, and TKE dissipation rate (Frehlich et al. 2003). When used in profiling mode, the TLS can collect continuous high-resolution profiles from the surface up to heights of several hundred metres. The TLS capabilities for observing detailed mean wind speed and temperature profiles, as well as turbulence dissipation rates, is proven in numerous field experiments (Balsley et al. 2003; Frehlich et al. 2006). In the deployment presented here, the TLS carried an instrument package similar to that of Frehlich et al. (2008), including $1.25 \mathrm{~mm}$ length and $5 \mu \mathrm{m}$ diameter Tungsten wires for $1 \mathrm{kHz}$ hotwire anemometer velocity measurements and $1 \mathrm{KHz}$ coldwire anemometer temperature measurements (Auspex Scientific, custom-made), $100 \mathrm{~Hz}$ thermistors (Honeywell 111-103EAJ-H01) and solid-state measurements for temperature (Analog Devices Inc TMP36) and relative humidity (Honeywell HIH-4000), a $100 \mathrm{~Hz}$ pitot tube (Dwyer instruments model 166-6) and pressure sensor (Honeywell DC001NDC4) for velocity and pressure measurements, as well as GPS and compass measurements. The GPS measurements of latitude, longitude, and altitude are sampled every $5 \mathrm{~s}$ and are estimated to have a positional error of less than $2.5 \mathrm{~m}$ by the manufacturer. GPS measurements are sampled every $5 \mathrm{~s}$. The GPS altitude measurements were not deemed sufficient, so altitude was calculated from pressure measurements.

\subsection{The National Wind Technology Center}

The measurement campaign was carried out at the National Wind Technology Center (NWTC), a research and development facility operated by the U.S. Department of Energy's National Renewable Energy Laboratory (NREL) just south of Boulder, Colorado. A 1.5 MW GE SLE wind turbine is available for research and testing, with a hub height of $80 \mathrm{~m}$ and a rotor diameter $D$ of $77 \mathrm{~m}$, representative of current wind-turbine deployments (Wiser and Bollinger 2013). The TLS was flown from a base located east of this turbine (Fig. 1).

To the west-north-west of this turbine at a distance of approximately $160 \mathrm{~m}$, the $135-\mathrm{m}$ M5 meteorological tower provides detailed meteorological profiles with six levels of sonic anemometers $(15,41,61,74,100$, and $119 \mathrm{~m}), 10$ levels of cup anemometers $(3,10,30,38$, $55,80,87,105,122$, and $130 \mathrm{~m})$, and four levels of temperature measurements $(3,38,87$, and $122 \mathrm{~m}$ ) (Clifton et al. 2013). The booms on this tower are directed to $278^{\circ}$ to capitalize on the most frequent direction for strong winds at the NWTC. These winds tend to be funneled from Eldorado Canyon, $5 \mathrm{~km}$ to the west of the NWTC (Banta et al. 1996). Because the NWTC site experiences flow heterogeneity due to the complex terrain $5 \mathrm{~km}$ to the west of the site (Aitken et al. 2014a, b), data from the M4 tower were also used, located $750 \mathrm{~m}$ south-south-west of the M5 tower. The M4 tower features arrays of sonic and cup anemometers similar to that of the M5 tower. Maps of the towers, turbine, and TLS measurements appear in (Fig. 1). 


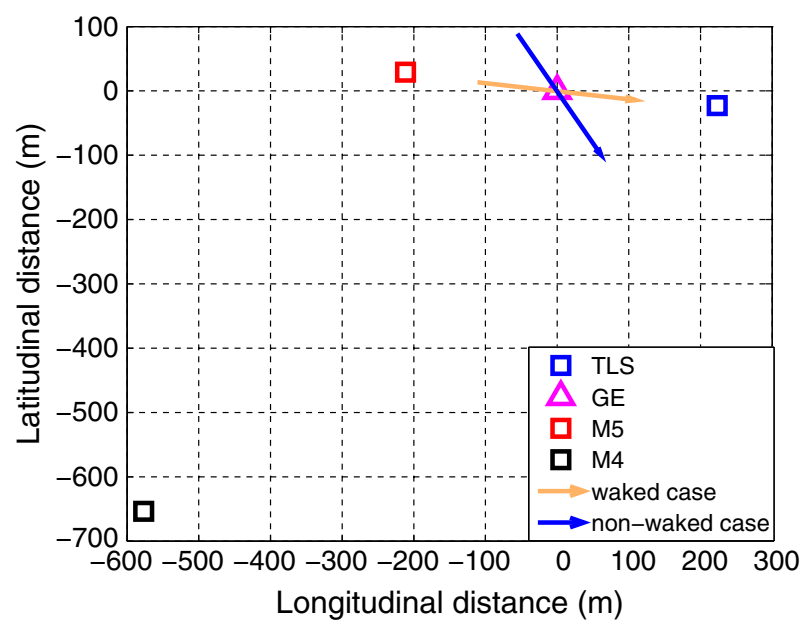

Fig. 1 Map of the NWTC test site region, highlighting the locations of the GE turbine (pink triangle), the TLS base (blue square), and the meteorological towers (M5: red square, M4: black square). The arrows show the M5 80-m wind direction for the case in which the TLS does not measure wake (orange arrow) and the case in which the TLS does measure wind turbine wake (blue arrow). The origin of this map is located at the GE turbine

The tower data provide a quantification of atmospheric stability via the Obukhov length, $L$, defined as

$$
L=-\frac{\left(\overline{u^{\prime} w^{\prime}}\right)^{3}}{\kappa \frac{g}{T_{0}}\left(\overline{w^{\prime} T_{v}^{\prime}}\right)},
$$

where $k$ is the von Kármán constant, $g$ is the acceleration due to gravity, $T_{o}$ is the average air temperature as measured by the 3 -m thermometer, and the momentum $\left(\overline{u^{\prime} w^{\prime}}\right)$ and buoyancy $\left(\overline{w^{\prime} T_{v}^{\prime}}\right)$ fluxes are calculated using eddy covariance from time series of the streamwise $(u)$ and vertical $(w)$ wind components and virtual temperature $\left(T_{v}\right)$ observed by the sonic anemometers at the 15-m level (the lowest level available) on the towers (Stull 1988). Denoting the measurement height as $z$, then $z / L<0$ represents unstable conditions and $z / L>0$ represents stable conditions. In neutral conditions, as observed in the cases discussed here, $L \rightarrow \infty$, and $z / L=0$.

\subsection{Dissipation Calculations}

From fast-response anemometers such as on the TLS system, the inertial dissipation method may be used to quantify the TKE dissipation rate $\varepsilon$ (Piper and Lundquist 2004). The inertial dissipation technique applies inertial subrange theory to estimate $\varepsilon$ based on velocity spectral values in the inertial subrange, assuming that the sensor has an adequate frequency response to resolve the inertial subrange. The TLS hotwire time series and the tower-based sonic anemometers both provide a means of estimating the dissipation rate using the inertial dissipation method (Champagne et al. 1977; Fairall et al. 1990; Oncley et al. 1996). In the inertial subrange of frequencies $f$, the power spectrum of a velocity component $S_{U}$ is assumed to be given by 


$$
S_{U}(f)=\alpha\left(\frac{\varepsilon \bar{U}}{2 \pi}\right)^{2 / 3} f^{-5 / 3},
$$

where the Kolmogorov constant $\alpha$ is here assumed to be 0.52 , based on Fairall and Larsen (1986). This value is within the range found in previous studies and close to the value 0.50 suggested by Sreenivasan (1995). Equation 2 can be rearranged to give

$$
\varepsilon=\left(\frac{2 \pi}{\bar{U}}\right)\left[\frac{f^{5 / 3} S_{U}(f)}{\alpha}\right]^{3 / 2} .
$$

For calculations based on the TLS observations, we computed power spectra based on data from 1-s time windows and applied the inertial estimation method based on the 1$10 \mathrm{~Hz}$ frequency range of the spectra from the TLS as in Eq. 3. For calculations from the M4 and M5 tower sonic anemometer data, we selected 1-min time windows of data from sonic anemometers; for each sonic anemometer, the relevant window was centered on the time when the TLS was located at the altitudes of that anemometer. Dissipation rates were then estimated with the inertial dissipation technique based on the power spectra in the 0.5$7 \mathrm{~Hz}$ frequency range. Because some time periods were affected by M5 sonic anemometer malfunctions, in some cases the time window was shortened or shifted slightly. The M4 data were unaffected by these malfunctions.

In the presentation of dissipation rate in the following, inertial dissipation estimates include an error analysis following Piper (2001). Because the inertial dissipation method relies on spectral estimates taken over several frequency bands, the spread of the spectral estimates quantifies the uncertainty in the estimates of dissipation rate. If $I$ is the sample mean value of $f^{\frac{5}{3}} S_{u}(f)$, which has a variance value of $\sigma_{I}^{2}$, where $\sigma_{I}$ is the standard deviation of the values of $f^{\frac{5}{3}} S_{u}(f)$ in the frequency band of interest, then, following Piper (2001), the error (s) in the inertial dissipation estimate is given by

$$
\sigma_{\varepsilon}=\frac{3}{2} \varepsilon \frac{\sigma_{I}}{I} .
$$

These errors appear in Figs. 2, 3, 4, 5 and 6 as error bars.

\section{Results}

\subsection{Measurements of Undisturbed Flow}

A case with flow from the north provides "undisturbed" measurements at both the TLS site and the M5 meteorological tower to quantify the agreement between these instruments. The TLS profiles for this "undisturbed" case occurred between 2100 and 2200 UTC on 29 October 2012. TLS, M5, and M4 measurements indicate wind directions between north-west and north $\left(300^{\circ}-360^{\circ}\right.$, Fig. $2 \mathrm{a}$, with some variability between the two meteorological towers) and wind speeds between 2 and $4 \mathrm{~m} \mathrm{~s}^{-1}$ (Fig. 2b). Atmospheric stability, based on data from the 15-m sonic anemometer at the M5 meteorological tower, was stable with $z / L=3$. If a wake was generated by the wind turbine during this time period, the wake would propagate into a region unsampled by the TLS or either tower (Fig. 1), and so these measurements provide an opportunity for comparing the wind speed and $\varepsilon$ measurement capabilities of the TLS and the towers unaffected by the wake. 

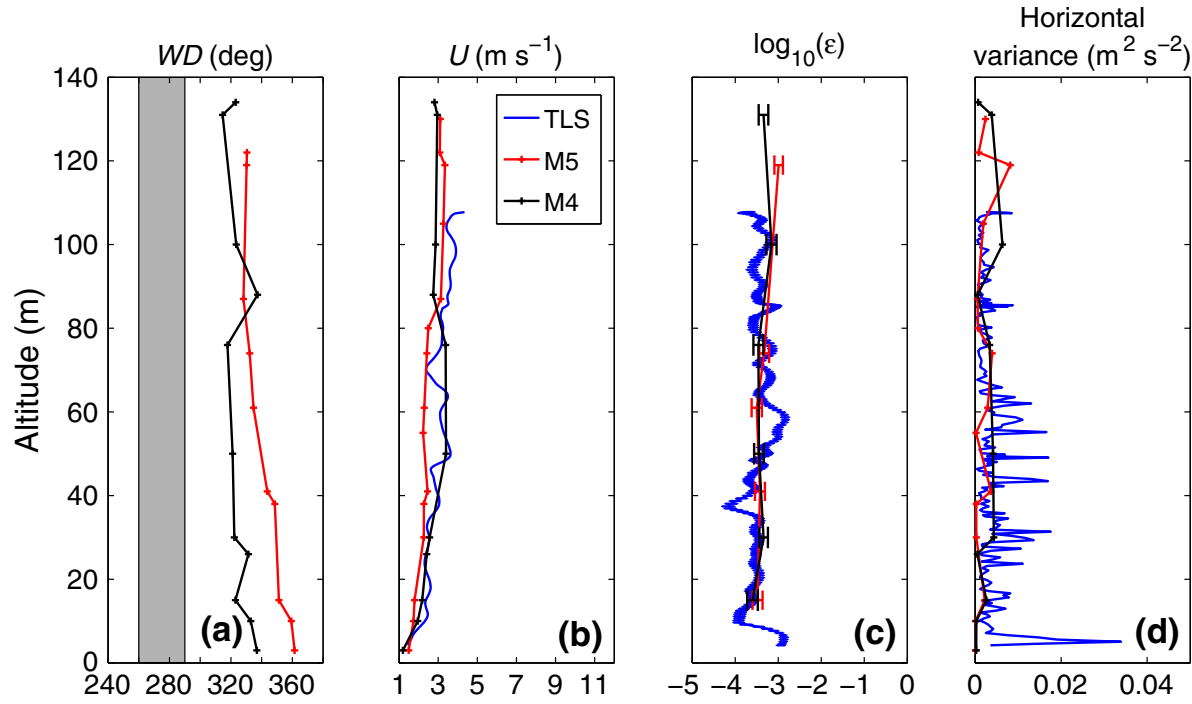

Fig. 2 Profiles of observations collected during the non-wake case. The TLS observations are in blue while the towers are in red (M5) and black (M4). Left wind direction, illustrating that the wake does not propagate towards the TLS. The grey region highlights the wind directions in which the wake would influence the TLS measurement. Centre left wind speed from all three platforms, showing low wind speeds and good agreement between the platforms. Centre right dissipation rate estimates using the inertial dissipation method from all three platforms, showing good agreement and emphasizing the capabilities of the TLS to collect refined measurements between the altitudes of the sonic anemometers on the meteorological towers. Left the variance in horizontal wind speed as measured by all platforms collected over a 1-min period

Observations of wind speed and dissipation rate from all platforms are consistent for this case within the range of variability expected at this site (Aitken et al. 2014a). The profile of wind speed measured by the TLS (Fig. 2b), based on 1-s averages, closely follows the profiles measured by the two meteorological towers (based on 1-min averages) with wind speeds within $0.8 \mathrm{~m} \mathrm{~s}^{-1}$ and slightly better agreement with the more distant M4 tower. Previous studies at the NWTC have noted the variability across the site (Aitken et al. 2014a), which could explain the agreement between the TLS and M4. Inertial dissipation estimates of dissipation rate from the tower and the TLS system exhibit good agreement (Fig. 2c). In fact, the TLS estimates of dissipation rate lie within the error bars of the sonic measurements at all altitudes except at 60-m height. At that height, the differences are still less than an order of magnitude. We conclude that these two platforms, the TLS and the tower sonic anemometers, can independently measure the same behaviour. The TLS profiles of dissipation exhibit more vertical variability than can be observed with the set of six sonic anemometers on the tower. In previous studies, the TLS has also observed very fine-scale vertical structure in dissipation rate (Muschinski et al. 2001; Frehlich et al. 2003), including increased dissipation near the ground at levels below the lowest tower measurement.

\subsection{Measurements of Waked Flow with the TLS}

In the late afternoon of 13 November 2012 (2319-2354 UTC), a profile obtained with the TLS was located squarely in the wake of the GE turbine during west-south-westerly winds (Fig. 3a). (The profile presented here required a 25-min observation period.) The base of the 

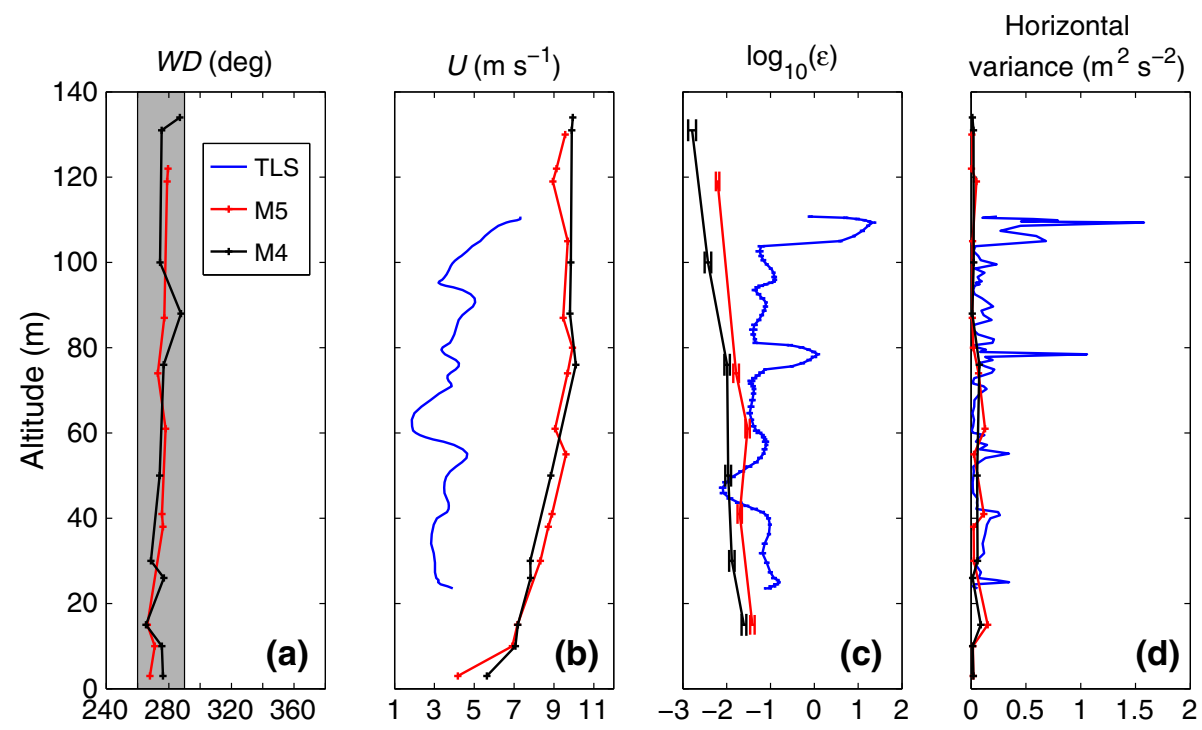

Fig. 3 Profiles of observations collected during the wake case. The TLS observations are in blue while the towers are in red (M5) and black (M4). Left wind direction, illustrating that the wake propagates towards the TLS. The grey region highlights the wind directions in which the wake would influence the TLS measurement. Centre left wind speed from all three platforms, showing moderate wind speeds and a sizeable wake wind speed deficit measured by the TLS compared to the upwind towers. Centre right dissipation rate estimates using the inertial dissipation method from all three platforms, showing the enhancement of dissipation rate in the wake. Left the variance in horizontal wind speed as measured by all platforms collected over a 1-min period

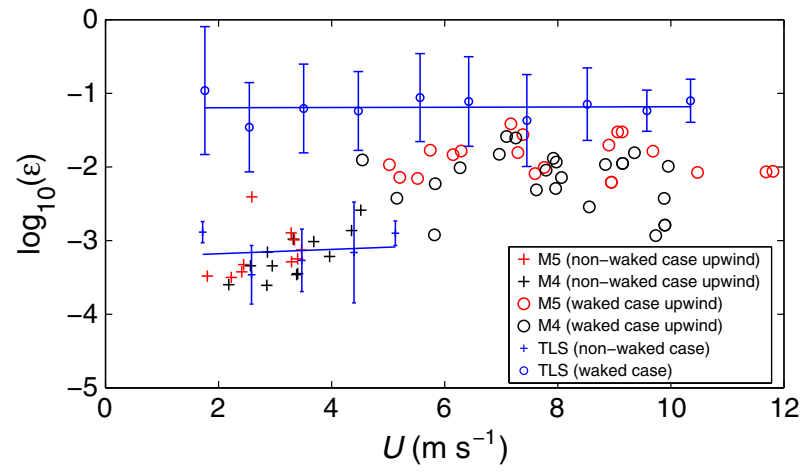

Fig. 4 Variability of dissipation rate with wind speed, incorporating measurements from both waked and non-waked measurements. The wind-speed measurements correspond to the altitudes of the dissipation rate measurements. The best-fit lines appear in the text

TLS was again located $160 \mathrm{~m}(\approx 2 D)$ west of the turbine (Fig. 1). Wind profiles upwind of the turbine, as measured from the meteorological tower, showed speeds ranging from $4 \mathrm{~m}$ $\mathrm{s}^{-1}$ near the surface to $11 \mathrm{~m} \mathrm{~s}^{-1}$ aloft (Fig. 3b). Atmospheric stability, using the $15-\mathrm{m}$ sonic anemometer at the M5 meteorological tower, was near-neutral, with $z / L=0.07$. According to the TLS, the wake wind-speed deficit is significant: wind-speed profiles measured by the TLS are between 1 and $5 \mathrm{~m} \mathrm{~s}^{-1}$, resulting in a wake deficit of 30-60\%, similar to that 


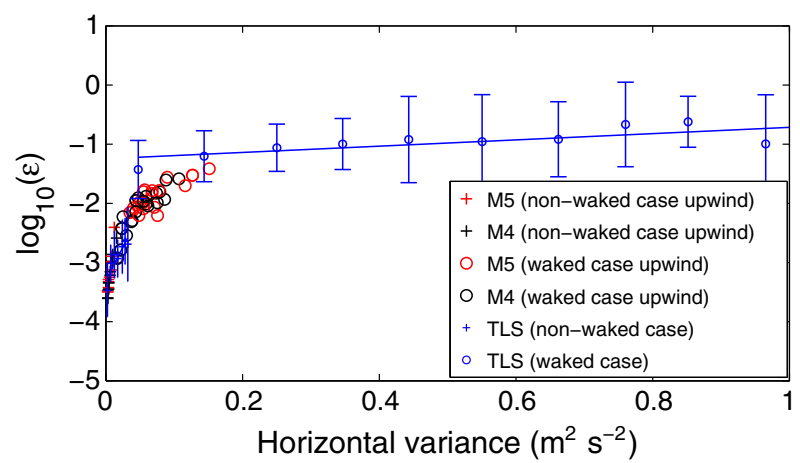

Fig. 5 Variability of dissipation rate with horizontal variance $\sigma_{U}^{2}$, incorporating measurements from both waked and non-waked measurements. The wind-speed variance measurements are calculated over a 1-min period and correspond to the altitudes of the dissipation rate measurements. The best-fit lines appear in the text

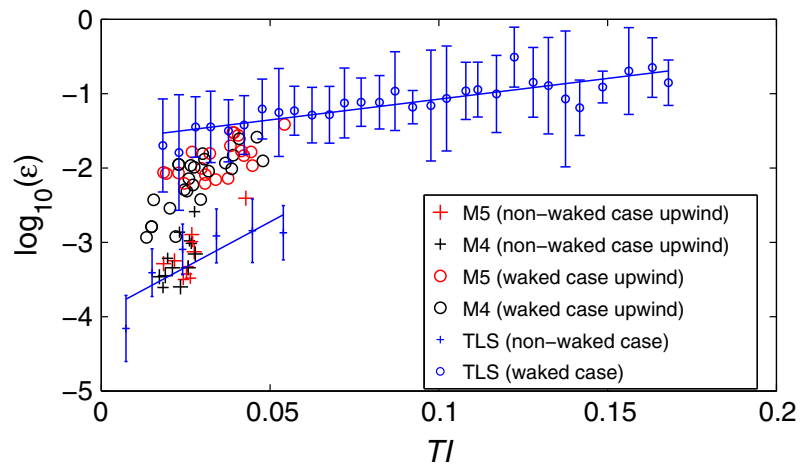

Fig. 6 Variability of dissipation rate with turbulence intensity $T I$, incorporating measurements from both waked and non-waked measurements. The wind-speed variance and wind-speed measurements for TI are calculated over a 1-min period and correspond to the altitudes of the dissipation rate measurements. The best-fit lines appear in the text

observed by Rhodes and Lundquist (2013) at moderate wind speeds in the constant-pitch region of the turbine's power curve.

Given the high wind speeds in this case, both tower and TLS estimates of dissipation are much higher than in the northerly flow case (Fig. 3c). The dissipation measurements from the TLS are markedly distinct from the dissipation profiles calculated at the towers (Fig. 3c), likely because the wind turbine located between the tower and the TLS measurements generates considerable TKE that is advected and then dissipated downwind. The TLS measured $\varepsilon$ between one and two decades higher than measurements at either of the meteorological towers. Distinct shallow layers of elevated $\varepsilon$ appear at hub height and in the top half of the rotor disk; such extreme gradients have been observed previously with this platform (Balsley et al. 2003).

\subsection{Variability of $\varepsilon$ Within and Outside of a Turbine Wake}

Parametrizations of $\varepsilon$ in numerical weather prediction models, with grid cells $\sim 1 \mathrm{~km}$ or coarser, emphasize the dependence of dissipation rate on wind speed or on turbulence within 
a given simulation grid cell (Mellor 1973). Some investigators (e.g. Nakanishi 2001; Hartogensis and Bruin 2005) have explored the dependence of $\varepsilon$ on stability. Unfortunately, the limited set of cases available here limits our ability to explore the role of atmospheric stability. (A significant number of other experiments required the use of the turbines at this site during the limited time available for the TLS deployments. Further, NWTC flight safety requirements limited TLS flights to daylight hours, wind speeds less than $15 \mathrm{~m} \mathrm{~s}^{-1}$, and no precipitation. The TLS is suitable for nighttime measurements, as well as in higher windspeed conditions.) For wind-energy applications with simulations at resolution $\sim 1-10 \mathrm{~m}$, Kasmi and Masson (2008) suggested that enhanced values of $\varepsilon$ in the near-wake region are appropriate although most investigators confine this zone of enhanced dissipation to the region within $0.25 \mathrm{D}$ of a turbine. Adoption of this correction in the near-rotor area does not completely improve predictions (Prospathopoulos et al. 2011), although most studies focus on agreement with observations of wind-speed deficit and turbulence intensity (TI), and not with actual measurements of dissipation rate (Cabezón et al. 2011).

To enable other investigators to incorporate these observations into numerical models, we express our results in terms of how dissipation rate varies within a "waked" regime and a "non-waked" regime, recognizing that there is likely variability within the "waked" regime that is not sampled with this set of observations. Variation with wind speed appears in Fig. 4. Although only low wind-speed observations were available for the non-waked case, the waked measurements span low and high wind speeds with $\varepsilon$ values approximately one to two orders of magnitude higher than in the non-waked case. These elevated levels of dissipation are consistent with those observed in other disturbed flows such as aircraft vortices (Frech 2007), frontal passages (Piper and Lundquist 2004), or in the entrainment zone at the top of an internal boundary layer (Klipp and Mahrt 2003). Clear differences between waked and non-waked measurements suggest that different parametrizations are required within wake regions than for non-wake regions. The best-fit line for the non-waked measurements is given by

$$
\varepsilon_{\text {nonwaked }}=0.029 U^{-3.24}
$$

while the best-fit line for the waked measurements is given by

$$
\varepsilon_{\text {waked }}=0.0017 U^{-1.2} \text {. }
$$

Numerical simulations typically express $\varepsilon$ as a function of the total TKE (Mellor 1973; Nakanishi 2001). As vertical velocity is not currently measured by the TLS, we cannot calculate the TKE corresponding to the locations where the TLS measures dissipation rate. Rather, we can explore the variation of $\varepsilon$ as a function of the horizontal wind-speed variance, $\sigma_{U}^{2}$ (Fig. 5). (Note that to facilitate the comparison of the TLS and tower measurements, the variance in both cases is calculated over a 1-min period.) Although considerable scatter exists, the waked measurements and the non-waked measurements inhabit different regimes with the waked dissipation rate typically 1-2 orders of magnitude larger than the non-waked measurements. The best-fit line for the non-waked measurements is given by

$$
\varepsilon_{\text {nonwaked }}=22.73\left(\sigma_{U}^{2}\right)^{-3.3},
$$

while the best-fit line for the waked measurements is given by

$$
\varepsilon_{\text {waked }}=0.53\left(\sigma_{U}^{2}\right)^{-1.25} \text {. }
$$

$T I$ is often used in wind-energy engineering to classify flow regimes although it does not acknowledge the role of vertical motions induced by buoyancy or shear, which can be important in strongly unstable cases, unlike the neutral cases here. The TI is defined as the 
ratio of the standard deviation of the horizontal wind speed $\left(\sigma_{U}\right)$ to the mean horizontal wind speed $\bar{U}$ (although it is often expressed as a percentage)

$$
T I=\frac{\sigma_{U}}{U} .
$$

As seen in Fig. 6, the best-fit line for the non-waked measurements is given by

$$
\varepsilon_{\text {nonwaked }}=24.38(T I)^{-3.94},
$$

while the best-fit line for the waked measurements is given by

$$
\varepsilon_{\text {waked }}=0.53(T I)^{-1.63} \text {. }
$$

Dissipation rates within wakes are distinctly enhanced from those outside of wakes, whether $\varepsilon$ is compared to wind speed $U$, wind speed variance $\sigma_{U}^{2}$, or normalized variance $T I$. These measurements suggest that fundamentally different modeling approaches should be taken within wakes as compared to outside of wakes to accommodate the enhanced dissipation with wakes.

\section{Discussion and Future Work}

Using a TLS, we have collected the first measurements of TKE dissipation rate in the wake of a multi-MW wind turbine. Dissipation rate measurements from a $1 \mathrm{kHz}$ hotwire anemometer lofted by a TLS agree well with those from conventional tower-mounted sonic anemometers in a flow unaffected by a wind-turbine wake. TLS measurements were also collected within a wind-turbine wake and compared to tower measurements upwind of the turbine. In the wake, the TLS measures dissipation rates one to two orders of magnitude higher than measurements upwind of the turbine. These data, collected between two and three rotor diameters $D$ downwind of the turbine, document the significant enhancement of TKE dissipation rate within the wind-turbine wake. These wake measurements suggest that it may be useful to pursue modelling approaches that account for enhanced dissipation.

Although a detailed modelling study is beyond the scope of the present work, we seek to facilitate the incorporation of these results into modelling schemes. Therefore, we summarize these observations of dissipation rate variability as a function of wind-speed, of horizontal wind-speed variance, and of TI. The present dataset can provide useful benchmarks for turbine-resolving modelling studies (e.g. Churchfield et al. 2012; Mirocha et al. 2014; Bhaganagar and Debnath 2014, among others).

These initial measurements could be extended to provide more insight into wake variability. Future measurement campaigns can exploit collaborative measurements of dissipation rate using in situ measurements as used here and estimates from scanning lidar (e.g. Smalikho et al. 2013; Aitken and Lundquist 2014c) to assess the variability of dissipation throughout turbine wakes and the validity of Taylor's frozen turbulence hypothesis for wake measurements. Dissipation likely reaches a maximum value at some distance downwind of the turbine and then decays further downwind. An integrated set of field measurements would enable the development of more refined approaches for considering the effect of turbulence dissipation on the evolution of wind-turbine wakes. As atmospheric stability and ambient turbulence clearly affect turbine power production (Wharton and Lundquist 2012; Vanderwende and Lundquist 2012) and turbine wake dynamics (e.g. Magnusson and Smedman 1994; Aitken et al. 2014a), such field measurements should span a range of stability conditions as well as inflow wind speeds. Transects of measurements with unmanned aerial systems 
(e.g., Lawrence and Balsley 2013) could assess dissipation variability at several locations within a wake simultaneously towards quantifying dissipation rate as a function of distance downwind from the turbine. Previous work has shown that turbulence in a wake is likely not isotropic (Browne et al. 1987), and so measurements of all the components of the TKE budget would enable quantification of error in dissipation estimates. Further, the complex terrain of the Rocky Mountains is located $5 \mathrm{~km}$ upwind of this site, and it is possible that terrain-enhanced turbulence influences the results discussed herein: measurements in other locations (onshore and offshore) could be pursued. More accurate understanding and prediction of wake dynamics will ultimately enable improved wind-farm layout and wind-turbine control optimization, reducing the cost of energy.

Acknowledgments This work was supported by a seed grant from Colorado Research and Education in Wind submitted by Prof. J. K. Lundquist and Dr. Yannick Meillier with cooperation from NREL. NREL is a National Laboratory of the U.S. Department of Energy, Office of Energy Efficiency and Renewable Energy, operated by the Alliance for Sustainable Energy, LLC. The authors thank NREL staff Dr. Andrew Clifton, Mr. Michael Stewart, Mr. Jeroen van Dam, and University of Colorado at Boulder researchers and students Michael Rhodes, Matthew Aitken, Brian Vanderwende, Ryan King, Clara St. Martin, and Josh Aikens for their considerable efforts in collecting these data, and Michael Rhodes for assistance with the figures. The authors also acknowledge Dr. Chris Fairall, Dr. Branko Kosović, and Dr. Andrew Clifton for helpful discussions, as well as the helpful comments of three anonymous reviewers.

Open Access This article is distributed under the terms of the Creative Commons Attribution License which permits any use, distribution, and reproduction in any medium, provided the original author(s) and the source are credited.

\section{References}

Aitken ML, Lundquist JK, Pichugina YL, Banta RM (2014a) Quantifying wind turbine wake characteristics from scanning remote sensor data. J Atmos Ocean Technol 31:765-787. doi:10.1175/ JTECH-D-13-00104.1

Aitken ML, Kosovic B, Mirocha JD, Lundquist JK (2014b) Large eddy simulation of wind turbine wake dynamics in the stable boundary layer using the Weather Research and Forecasting Model. J Renew Sustain Energy 6:033137. doi:10.1063/1.4885111

Aitken ML, Lundquist JK (2014c) Utility-scale wind turbine wake characterization using nacelle-based longrange scanning lidar. J Atmos Ocean Technol 31:1529-1539

Balsley BB, Frehlich RG, Jensen ML, Meillier Y, Muschinski A (2003) Extreme gradients in the nocturnal boundary layer: structure, evolution, and potential causes. J Atmos Sci 60:2496-2508. doi:10.1175/ 1520-0469(2003)060<2496:EGITNB > 2.0.CO;2

Banta RM, Olivier LD, Gudiksen PH, Lange R (1996) Implications of small-scale flow features to modeling dispersion over complex terrain. J Appl Meteorol 35:330-342. doi:10.1175/1520-0450(1996)035<0330: IOSSFF $>2.0 . \mathrm{CO} ; 2$

Barthelmie RJ, Pryor SC, Frandsen ST, Hansen KS, Schepers JG, Rados K, Schlez W, Neubert A, Jensen LE, Neckelmann S (2010) Quantifying the impact of wind turbine wakes on power output at offshore wind farms. J Atmos Ocean Technol 27:1302-1317. doi:10.1175/2010JTECHA1398.1

Bhaganagar K, Debnath M (2014) Effect of mean atmospheric forcings of stable atmospheric boundary layer on wind turbine wake. J Renew Sustain Energy (accepted with revision)

Browne LWB, Antonioa RA, Shah DA (1987) Turbulent energy dissipation in a wake. J Fluid Mech 179:307326. doi:10.1017/S002211208700154X

Cabezón D, Migoya E, Crespo A (2011) Comparison of turbulence models for the computational fluid dynamics simulation of wind turbine wakes in the atmospheric boundary layer. Wind Energy 14:909-921. doi:10. $1002 /$ we. 516

Calaf M, Meneveau C, Meyers J (2010) Large eddy simulation study of fully developed wind-turbine array boundary layers. Phys Fluids 22:015110. doi:10.1063/1.3291077

Calaf M, Parlange MB, Meneveau C (2011) Large eddy simulation study of scalar transport in fully developed wind-turbine array boundary layers. Phys Fluids 23:126603. doi:10.1063/1.3663376 
Champagne FH, Friehe CA, LaRue JC, Wyngaard J (1977) Flux measurements, flux estimation techniques, and fine-scale turbulence measurements in the unstable surface layer over land. J Atmos Sci 34:515-530. doi:10.1175/1520-0469(1977)034<0515:FMFETA >2.0.CO;2

Churchfield MJ, Lee S, Michalakes J, Moriarty PJ (2012) A numerical study of the effects of atmospheric and wake turbulence on wind turbine dynamics. J Turbul 13:1-32

Clifton A, Schreck S, Jager D, Kelley N, Lundquist JK (2013) Meteorological tower observations at the National Renewable Energy Laboratory. J Sol Energy Eng 135:031017. doi:10.1115/1.4024068

El Kasmi A, Masson C (2008) An extended model for turbulent flow through horizontal-axis wind turbines. J Wind Eng Ind Aerodyn 96:103-122. doi:10.1016/j.jweia.2007.03.007

Fairall CW, Larsen SE (1986) Inertial-dissipation methods and turbulent fluxes at the air-ocean interface. Boundary-Layer Meteorol 34:287-301

Fairall CW, Edson JB, Larsen SE, Mestayer PG (1990) Inertial-dissipation air-sea flux measurements: a prototype system using realtime spectral computations. J Atmos Ocean Technol 7:425-453. doi:10. 1175/1520-0426(1990)007<0425:IDASFM>2.0.CO

Farm J, Kwon S, Law HK (2013) Wind farm power maximization based on a cooperative static game approach. SPIE, San Diego

Fitch AC, Olson JB, Lundquist JK, Dudhia J, Gupta AK, Michalakes J, Barstad I (2012) Local and mesoscale impacts of wind farms as parameterized in a Mesoscale NWP Model. Mon Weather Rev 140:3017-3038. doi:10.1175/MWR-D-11-00352.1

Fitch A, Lundquist JK, Olson JB (2013) Mesoscale influences of wind farms throughout a diurnal cycle. Mon Weather Rev 141:2173-2198. doi:10.1175/MWR-D-12-00185.1

Frech M (2007) Estimating the turbulent energy dissipation rate in an airport environment. Boundary-Layer Meteorol 123:385-393. doi:10.1007/s10546-006-9149-2

Frehlich R, Meillier Y, Jensen M, Balsley B (2003) Turbulence measurements with the CIRES tethered lifting system during CASES-99: calibration and spectral analysis of temperature and velocity. J Atmos Sci 60:2487-2495. doi:10.1175/1520-0469(2003)060<2487:TMWTCT>2.0.CO;2

Frehlich R, Meillier Y, Jensen M, Balsley B, Sharman R (2006) Measurements of boundary layer profiles in an urban environment. J Appl Meteorol Climatol 45:821-837. doi:10.1175/JAM2368.1

Frehlich R, Meillier Y, Jensen ML (2008) Measurements of boundary layer profiles with in situ sensors and Doppler lidar. J Atmos Ocean Technol 25:1328-1340. doi:10.1175/2007JTECHA963.1

GWEC (2013) Global Wind Report: Annual Market Update (2012). Available at http://www.gwec.net/ wp-content/uploads/2012/06/Annual_report_2012_LowRes.pdf

Hamilton N, Kang HS, Meneveau C, Cal RB (2012) Statistical analysis of kinetic energy entrainment in a model wind turbine array boundary layer. J Renew Sustain Energy 4:063105. doi:10.1063/1.4761921

Hartogensis O, de Bruin H (2005) Monin-Obukhov similarity functions of the structure parameter of temperature and turbulent kinetic energy dissipation rate in the stable boundary layer. Boundary-Layer Meteorol 116:253-276. doi:10.1007/s10546-004-2817-1

Jacobson MZ, Archer C (2012) Saturation wind power potential and its implications for wind energy. Proc Natl Acad Sci USA 109:15679-15684. doi:10.1073/pnas.1208993109

Kaffine D, Worley C (2010) The windy commons? Environ Resour Econ 47:151-172. doi:10.1007/ s10640-010-9369-2

Kelley ND (2004) An initial overview of turbulence conditions seen at higher elevations over the Western Great Plains. In: Proceedings of global wind power conference, Chicago

Kelley N, Shirazi M, Jager D, Wilde S, Adams J, Buhl M, Sullivan P, Patton E (2004) Lamar Low-Level Jet Program-Interim Report, Report No. NREL/TP-500-34593, National Renewable Energy Laboratory, Golden

Klipp C, Mahrt L (2003) Conditional analysis of an internal boundary layer. Boundary-Layer Meteorol 108:117. doi:10.1023/A:1023034932094

Lawrence DA, Balsley BB (2013) High-resolution atmospheric sensing of multiple atmospheric variables using the DataHawk small airborne measurement system. J Atmos Ocean Technol 30:2352-2366. doi:10.1175/ JTECH-D-12-00089.1

Lu H, Porté-Agel F (2011) Large-eddy simulation of a very large wind farm in a stable atmospheric boundary layer. Phys Fluids 23:065101. doi:10.1063/1.3589857

Magnusson M, Smedman AS (1994) Influence of atmospheric stability on wind turbine wakes. Wind Energy 18:139-151

Marden JR, Ruben SD, Pao LY (2012) Surveying game theoretic approaches for wind farm optimization. In: Proceedings of the AIAA aerospace sciences meeting

Mellor GL (1973) Analytic prediction of the properties of stratified planetary surface layers. J Atmos Sci 30:1061-1069 
Mirocha J, Kosovic B, Aitken M, Lundquist JK (2014) Implementation of a generalized actuator disk wind turbine model into WRF for large-eddy simulation applications. J Renew Sustain Energy 6:013104. doi:10.1063/1.4861061

Muschinski A, Frehlich R, Jensen M, Hugo R, Hoff A, Eaton F, Balsley B (2001) Fine-scale measurements of turbulence in the lower troposphere: an intercomparison between a kite- and balloon-borne, and a helicopter-borne measurement system. Boundary-Layer Meteorol 98:219-250

Nakanishi M (2001) Improvement of the Mellor-Yamada turbulence closure model based on large-eddy simulation data. Boundary-Layer Meteorol 99:349-378

Oncley S, Friehe CA, Larue JC, Businger JA, Itsweire EC, Chang SS (1996) Surface-layer fluxes, profiles, and turbulence measurements over uniform terrain under near-neutral conditions. J Atmos Sci 53:1029-1043. doi:10.1175/1520-0469(1996)053<1029:SLFPAT>2.0.CO;2

Piper M (2001) The effects of a frontal passage on fine-scale nocturnal boundary layer turbulence. PhD thesis, University of Colorado

Piper M, Lundquist JK (2004) Surface layer turbulence measurements during a frontal passage. J Atmos Sci $61: 1768-1780$

Prospathopoulos JM, Politis ES, Rados KG, Chaviaropoulos PK (2011) Evaluation of the effects of turbulence model enhancements on wind turbine wake predictions. Wind Energy 14:285-300. doi:10.1002/we.419

Rajewski Daniel A et al (2013) Crop wind energy experiment (CWEX): observations of surface-layer, boundary layer, and mesoscale interactions with a wind farm. Bull Am Meteorol Soc 94:655-672

Rhodes ME, Lundquist JK (2013) The effect of wind turbine wakes on summertime Midwest atmospheric wind profiles. Boundary-Layer Meteorol 149:85-103. doi:10.1007/s10546-013-9834-x

Sim C, Basu S, Manuel L (2009) The influence of stable boundary layer flows on wind turbine fatigue loads. In: Proceedings of the AIAA aerospace sciences meeting, Orlando

Smalikho IN, Banakh VA, Pichugina YL, Brewer WA, Banta RM, Lundquist JK, Kelley ND (2013) Lidar investigation of atmosphere effect on a wind turbine wake. J Atmos Ocean Technol 30:2554-2570

Sreenivasan KR (1995) On the universality of the Kolmogorov constant. Phys Fluids 7:2778-2784

Stull RB (1988) An introduction to boundary-layer meteorology. Kluwer Academic Publishers, Dordrecht, $666 \mathrm{pp}$

Thomsen K, Sørensen P (1999) Fatigue loads for wind turbines operating in wakes. J Wind Eng Ind Aerodyn 80:121. doi:10.1016/S0167-6105(98)00194-9

Vanderwende B, Lundquist JK (2012) The modification of wind turbine performance by statistically distinct atmospheric regimes. Environ Res Lett 7:034035. doi:10.1088/1748-9326/7/3/034035

Wharton S, Lundquist JK (2012) Atmospheric stability affects wind turbine power collection. Environ Res Lett 7:014005-1-014005-9

Wiser R, Bollinger M (2013) Wind Technologies Market Report. LBL Report LBNL-6356E. Available at http://emp.lbl.gov/publications/2012-wind-technologies-market-report 